\title{
Party Constituency Associations and the Service, Policy and Symbolic Responsiveness of Canadian Members of Parliament
}

\author{
Royce KoOP University of Manitoba
}

\section{Introduction}

Democratic theory rests on the notion that political actors learn of and respond to the needs and preferences of citizens (see, for example, Dahl, 1989; Key, 1961). Pitkin (1967: 209) classically argues that representation "is achieved in a ... continuous process, which depends on a level of responsiveness to the electorate." The process that Pitkin refers to is reciprocal: representatives must both learn of the needs and preferences of constituents and relay their representative accomplishments back to their constituents in order to establish a reputation for democratic responsiveness. Communication between representatives and constituents is therefore crucial; indeed, Jewell (1982: 18) argues that communication is itself an integral aspect of representation. The question then is what mechanisms do representatives rely on to maintain communication with and ensure responsiveness to their constituents?

Political parties, traditionally understood as the crucial intermediary linkage between citizens and the state, play a key role in maintaining communication linkages between representatives and their constituents. However, Canadian parties are not seen to perform this role particularly well for three reasons. First, the elite brokerage tendency of national party leaders has meant that parties have not been open to the policy and ideological preferences of those they represent (see, for example, Carty and Cross, 2010). Second, Canadian parties are highly disciplined, even by

Acknowledgments: I wish to thank Harold Jansen and the journal's anonymous reviewers for their comments, Erika Kirkpatrick for providing research assistance and John Richards for translating the abstract. I gratefully acknowledge financial support in the form of two postdoctoral fellowships from Memorial University and the SkeltonClark Foundation at Queen's University.

Royce Koop, Department of Political Studies, University of Manitoba, 532 Fletcher Argue, Winnipeg MB, R3T 5V5, royce.koop@ad.umanitoba.ca 
Westminster standards, limiting the ability of individual members of Parliament (MPs) to effectively represent the interests and preferences of their constituents in Parliament (Malloy, 2003: 117-20). Finally, the components of Canadian parties that might play a direct role in facilitating communication between citizens and government, their constituency associations, are thought to be quite evanescent, forming in the lead-up to nomination and leadership races and essentially closing up shop afterward (see Wolinetz, 2007: 185). Given their lack of rootedness and permanence in the communities of the ridings, these organizations are in a poor position to act as intermediaries between representatives and citizens.

This article draws on 46 interviews with sitting MPs and local party officials as well as observation in the ridings to explore the role of Canadian party constituency associations in the process of local representation. It makes the contradictory argument that these constituency associations play important representational roles by facilitating communication between MPs and their constituents. Members of constituency association executives do so by conveying the needs and preferences of constituents to MPs and disseminating the representative accomplishments of MPs to constituents. Sector representatives - citizens from defined local groups on association executives-provide a means for focused communication between MPs and certain constituents. Constituency association executives also often act as local focus groups, assisting MPs in tailoring their communications for the consumption of their constituents. By facilitating communication between MPs and their constituents, members of association executives enhance the three types of representative responsiveness identified by Eulau and Karps (1977: 241): service, policy and symbolic. In demonstrating how constituency associations facilitate communication, this article elucidates an important and largely unrecognized function of Canadian political parties in the process of representation in the ridings (but see McMenemy, 1989; Price and Mancuso, 1995: 217-18) and situates Canadian parties in a comparative literature that emphasizes the linkage benefits provided by local party organizations between election campaigns (see Clark, 2004).

In addition to contributing to our understanding of the role of Canadian political parties in the representational process, this article adds to the academic literature on the functions of local party organizations in developed democracies. There has for some time been disagreement over the usefulness of party members and local party organizations to political parties. Those arguing for the usefulness of local organizations have focused on their direct electoral benefits for parties and candidates (Carty and Eagles, 2005; Denver and Hands, 2007; Whiteley and Seyd, 2003). However, there has been less emphasis on the inter-election functions and benefits of local organizations. By assisting incumbent MPs in their representative roles, constituency association executives allow MPs to bet- 
Abstract. Effective representation requires that representatives learn of the needs and preferences of their constituents and communicate their representative accomplishments back to those constituents. This article demonstrates how Canadian political parties, specifically their constituency associations in the ridings, assist MPs in their representative functions by facilitating communication between MPs and constituents. Representatives of local "sectors" on constituency association executives provide a means for focused communication between MPs and constituents. The result is that constituency associations enhance the service, policy and symbolic responsiveness of many MPs in their ridings. This article therefore elucidates the largely unrecognized role of Canadian parties' constituency organizations as important democratic and representational actors in the ridings.

Résumé. Pour être efficace, il faut que les élus (1) comprennent les besoins et les préférences de leurs électeurs et (2) communiquent leurs activités en tant que parlementaires. Cet article montre à quel point les partis politiques canadiens, surtout les comités au niveau des comtés individuels, sont importants comme instrument pour réaliser ces tâches. Les comités organisent la communication entre un député et les groupes locaux qui s'intéressent au sujet en question. Pour résumer, les comités de militants fournit un element crucial au succès d'un politicien dans son comté. C'est une dimension de l'activité que les politiologues ont tendance à ignorer.

ter understand and act on behalf of their constituents, which is the first step in the development of a local "personal vote" (Blais et al., 2003); and adjust their legislative activities in response to their constituents' preferences and needs (Soroka et al., 2009), which can benefit MPs in future re-election campaigns. Constituency associations as communications agents therefore have indirect electoral benefits for MPs.

\section{Communication, Constituency Associations and Local Sectors}

How do Canadian MPs communicate with their constituents? MPs are provided with funds to hire staff who focus exclusively on riding matters and maintain accessible local offices that are open to visits from constituents (Docherty, 1997: 172). However, the usefulness of these offices is limited by the willingness of constituents to use them, and, as MacLeod (2006) points out, they are not typically organized in a welcoming manner. MPs send out questionnaires in their mailings and householders asking constituents for their preferences on issues. MPs also use town halls and other community gatherings to collect opinions from constituents (Docherty, 1997: 175).

Communicating representatives' views and accomplishments back to constituents is less difficult. MPs rely on news media-newspapers, radio, and television - to report on their representative activities. However, news media cannot always be counted on to provide coverage. To solve the problem of inattentive media, MPs often write regular columns in local newspapers, detailing their legislative and representational activities and providing their views on local issues. MPs also have in their communications arsenal mailings to constituents as well as house- 
holders that are sent to every residence in the riding (Docherty, 1997: 173).

However, these methods of communicating with constituents all have severe limitations. This helps to explain why MPs turn to their constituency associations to facilitate communication with constituents. Constituency associations represent the permanent organizational presence of Canadian parties in the ridings. Constituency associations consist of three components: the wider party membership in the riding; the small executive that is elected by party members at annual general meetings; and the smaller number of officers (including the president, vice-president, treasurer, and secretary) who are also generally elected by local party members. Constituency associations and their executives have several important functions in the ridings, including fundraising, maintaining membership lists, organizing candidate searches and nomination contests and providing incumbent support (Koop, 2010: 896-98). The traditional responsibility for candidate selection tends to produce wild fluctuations in local membership levels for Conservative and Liberal associations, as outsiders purchase memberships to support nomination candidates and subsequently allow those memberships to expire (Carty, 1991: 74). The NDP's resilient mass-style associations, in contrast, are more resistant to such swings.

Executives are elected by local party memberships as wholes. However, MPs, when they are present, typically exercise influence over the composition of executives. ${ }^{1}$ This is an informal power: MPs interfere in executive elections by encouraging certain figures from local communities to put themselves forward for election and by openly supporting them. When MPs intervene in this manner, they do so in order to ensure that loyalists are in place on the executive or to recruit figures that can be trusted to professionalize the constituency association (Koop, 2010: 90910). MPs also encourage members of different communities throughout their ridings to sit on their executives so that the resulting executives have a representative character. One MP referred to these communities as "local sectors," and I adopt the term here. Local sectors are defined simply as any group of citizens with a common characteristic within a given constituency that is recognized by the MP.

There are many such characteristics of sectors, including language and cultural communities, geographic communities, socio-economic groups, religions or even groups defined on the basis of shared values, such as environmentalism. The sectors recognized by MPs in their ridings are shaped by both objective and subjective factors. First, the objective composition of their ridings shapes MPs' conceptions of local sectors. An MP representing a constituency with a large number of unionized workers, for example, spoke of unions as a local sector; another MP for a riding containing a military base spoke of military families as a local 
sector; finally, an MP with a high proportion of low income earners recognized the poor as a local sector. In all of these cases, objective considerations informed MPs' conceptions of local sectors.

Second, the subjective manners in which MPs view their constituencies shape the sectors that they recognize (see Fenno, 1978). Objective considerations are filtered through MPs' own perceptions of and experiences in the ridings. Some MPs view their constituencies as diverse and so recognize many sectors while others view their ridings as less heterogeneous and so recognize fewer sectors. Partisanship is an important influence that shapes MPs' own perceptions of the ridings, and the distinctive local experiences of Conservative, Liberal, and NDP MPs are reflected in their differing conceptions of their ridings. NDP MPs, for example, recognize local activists concerned over issues such as women's rights and the environment as local sectors; however, none of the Conservative MPs I interviewed classified such groups in this manner.

For the purposes of this article, I distinguish between two objective types of sectors. The first type is geographic. MPs consciously hope to staff their constituency association executives with members from the different geographic regions that make up their ridings. MPs from rural ridings recognize such sectors. Significant distance may divide regions and separate MPs and their staff from concerns in far-flung regions. In these cases, MPs often turn to executive members from the different regions to maintain contact within their geographic sectors. The second sector type is non-geographic. These sectors include socio-economic, cultural and language groups within communities. Of these, MPs were most likely to identify cultural groups as distinctive sectors. This is naturally the case in urban ridings, as cultural and language barriers separate MPs and their staff from the concerns of different cultural communities as well as communities of new Canadians.

The presence of distinctive sectors within constituencies is important because MPs are concerned with maintaining communication with these different groups. One way to do so is to recruit representatives of these different sectors onto local constituency association executives. Once these sector representatives are members of the executive, MPs can communicate directly with them on a regular basis.

\section{Constituency Associations and Democratic Responsiveness}

This section demonstrates how executives augment MPs' representative capacities by facilitating communication between MPs and constituents. Eulau and Karps (1977) distinguish between three types of representational responsiveness, which provides a framework with which to explore how constituency association executives assist MPs in communicating 
with constituents. The first type of responsiveness is service responsiveness, which refers to both service and allocative needs. Service responsiveness relates to the efforts of representatives to assist constituents in dealing with government agencies while allocative responsiveness refers to representatives' efforts to secure benefits from the government for their ridings. Second, policy responsiveness refers to the extent to which representatives adopt and advocate policies that align with the preferences of those they represent or "the presence of a meaningful connection between constituent policy preferences or demands and the representative's official behaviour" (Eulau and Karps, 1977: 242). Finally, symbolic responsiveness, what Fenno (1978) calls "home style," refers to representatives' efforts to psychologically bond with their constituents in order to generate trust and support. These types of responsiveness organize the following three subsections.

Since little is known of the representative roles of constituency association executives, the use of a small-n methodology is appropriate to develop theory regarding this function (Lijphart, 1971: 685). These findings are derived from 38 open-ended and later semi-structured interviews with Canadian members of Parliament conducted between January and August 2010. All MPs sat in the 40th Parliament. MPs were selected for interviews on the basis of factors suspected to influence a range of behaviours, including whether and how they use their associations to augment their representative capabilities. Variation was sought in party affiliation, number of terms served, professional background, partisan history (whether and to what extent MPs were involved in party organizations prior to being elected) and their relative safety in their ridings. The MPs interviewed varied across all of these factors.

Of the MPs interviewed, 21 were Liberal, 10 were Conservatives, and 7 were members of the New Democratic Party caucus. Seventeen interviews were conducted by phone, 15 were conducted in-person in the MPs' Ottawa offices, and 6 were conducted in the MPs' constituency offices. ${ }^{2}$ Most of these interviews were recorded and subsequently transcribed. This allowed for the use of quotations from MPs in order to provide illustrations of the points made and to allow MPs to speak in their own voices (Sandelowski, 1994: 480).

Relying on a single source of information carries the risk of yielding biased and unreliable accounts. While interviews with MPs are the primary source of information for this article, "triangulating"-comparing results from different data sources or by using different methods of data collection (Mays and Pope, 2000: 51) — can strengthen the validity of findings in qualitative research. I did so in two ways. First, I collected corroborating data from different data sources by interviewing eight constituency association presidents who were in positions to discuss the 
extent to which MPs' accounts of executives' representational roles were accurate. Second, I employed a different method of data collection, observation of association executive meetings when MPs were in attendance, in order to see how MPs interacted with members of their executives and to observe firsthand the exchange of information between MPs and executive members.

This additional data for the most part corroborated the claims of MPs and enhanced my understanding of their interactions with executive members. In other cases, this additional data caused me to temper my interpretations of MPs' reports, though never substantially. Two presidents, for example, held unrealistically positive views regarding the extent to which MPs expressed the policy opinions of executive members to the party leader and caucus. The most interesting distinction uncovered between MPs and presidents was in the weight they placed on the representational and electoral functions of constituency associations. When asked how associations assisted MPs, MPs tended to emphasize the representational benefits of associations whereas presidents were more likely to emphasize their electoral benefits (that is, fundraising and campaign preparations). This finding illustrates how MPs must often take an active role in constructing executives that are able to assist them in their representational functions and encourage executive members to collect and distribute information, as the association members do not appear to naturally place as great an emphasis on these functions.

\subsection{Service responsiveness}

Executives assist MPs in communicating with constituents and contributing to MPs' reputations for service responsiveness in two ways. First, they familiarize themselves with service needs in their own distinctive sectors and transmit these needs to their MPs. Second, executive members assist in establishing responsiveness by communicating back to the citizens in their sectors what the MP has done to satisfy their service needs. The crucial setting for the transmission of this information is meetings of the local executive. There is some variation in this practice because executives differ substantially in the frequency with which they hold full meetings (Carty, 1991: 58) and a small number of MPs are reluctant to attend these meetings. When MPs do attend executive meetings, they use the occasion to collect information from the members in their capacities as sector representatives. ${ }^{3}$

MP1 makes a point of attending all executive meetings, and calls in when meetings take place while he is in Ottawa. An important reason for this is the opportunity that these meetings provide for him to learn about service needs in his riding. 
They're a sounding board, they usually meet once a month and they always give you their views ... I always spend probably twenty minutes at every meeting asking, "Well, what are you hearing around town, what issues are you hearing about?" ... They'll tell you where the people are, what people are talking about...

One reason that MPs value this function during executive meetings is that it allows them to avoid being blindsided by unknown service requirements. From their positions within their respective sectors, executive members are able to detect emerging service requirements and pass them along during executive meetings. As MP2 reports,

They are always looking at local issues that may have an impact on my job as MP and they will advise me, "Look out, this thing is coming!" So I find that extremely helpful to have people who are there [in the riding] every single day-I'm not, you know - who keep their ears to the ground and keep me up to date on local things that are important to constituents and that I may take upon myself to defend.

One of the archetypal representative types developed by Smith (2003: 56 ) is "the advocate," representatives who "do not wait for issues to come to them." Instead, these representatives are active in their communities, using local meetings and events to seek out service problems through which they can demonstrate their responsiveness to their constituents. The quote above illustrates how executive members allow MPs to stay ahead of emerging issues in the ridings and seek out opportunities to portray themselves as advocates for their constituents.

The roles played by executive members differ substantially depending on the sectors they represent. In urban ridings, executive members are likely to represent non-geographic sectors, particularly cultural groups and sometimes communities of recent immigrants within the ridings. By encouraging members of different cultural communities to sit on their executives and report on the service needs of members of those communities, MPs can overcome the obstacles associated with staying in contact with distinctive local communities.

Having a wide range of contacts in local cultural sectors to draw on, MPs turn to appropriate executive members when issues arise that affect their communities. MP3, for example, describes how crucial the Tamil representative on his executive was when that community was in the national news:

It [the executive] is my intelligence service, it has to do with my representational ability. For example, we have a sizeable Tamil population. During the Sri Lankan crisis this year, my three people on the executive that are Tamils, they kept me totally informed as to what the community was thinking. 
MP3 was in close contact with the Tamil executive members during this crisis. Since other MPs knew that his riding had a large Tamil population and that he had contacts in the local community, they inquired as to "what the community was thinking," and MP3 was able to relay the information that his executive members had gathered and reported.

The usefulness of these sector representatives means that MPs may go to great lengths to ensure that each cultural community in their riding is represented on the executive. The assistance of association presidents may be enlisted for this purpose. "There's a large Bangladeshi community [in the constituency] and during the last election there was one guy in particular that sort of emerged as a leader," notes one association president. "So we asked him to become actively involved in the riding association." To emphasize this point, an MP described his discomfort when he realized that another cultural community was not properly represented: "I have a sizeable community, 4000 Afghans, who live in this riding. I don't have an Afghan on my executive [and] I miss that. There's something wrong, I am not picking up what's going on in the Afghan community. I'm missing something, I can feel it."

In contrast, MPs in rural ridings emphasize the importance of geographically defined sector representatives on their executives. Rural MPs struggle to keep up to date on the service requirements of the many communities in their ridings, which may be very small in terms of population and separated by great distances. One way to overcome this problem and connect MPs with the service needs of rural constituents is to staff constituency association executives with representatives from each of these geographically defined sectors.

When asked about the benefits provided by their constituency associations, most rural MPs immediately point to this benefit. "I find that they're very good at keeping me connected because, you know, the riding is spread out quite a bit," says MP4. MP5 notes that his executive is a "communications vehicle" that is necessary because of the size of his riding:

Something that I do is I use them as a bit of a communications vehicle. My riding's bigger than Prince Edward Island, so I have those members that are on the [executive] hold their ears to the ground on some things that may be coming up in their particular areas that I might have missed or my staff might have missed or that wasn't in the paper or whatever... It's much different if you're in an urban riding where you jump on your bicycle and in twenty minutes you're around it.

Constituency associations also enhance the representative capacities of MPs by organizing events where MPs gather opinions from constituents. One of the important functions of constituency association executives is organizing inter-election maintenance events in order to maintain 
contact with constituents and reach out to different communities, presenting a friendly face to the party in the riding (Scarrow, 1996: 137). When incumbents are present, these inter-election events have the added benefit of allowing MPs to converse with constituents, gathering information on service requirements in the riding.

While executive members are useful when acting as low-level intelligence gatherers from their respective sectors, they are also useful for communicating MPs' actions back to constituents, thereby completing the two-way process necessary for effective representation to take place. At executive meetings, MPs are given opportunities to speak about their activities on behalf of constituents, providing association members with items to take back to their communities and disseminate.

One benefit of relying on executive members to communicate MPs' representative accomplishments is that these accomplishments can be presented in a partisan manner in order to enhance the MPs' re-election prospects. Through their informal conversations with friends and other members of their sectors, executive members can consciously link the representative accomplishments of MPs to partisan goals. MP5 explicitly makes this point:

I can't put anything out about fundraising, memberships, or donations. Those are all communications that I can't do through my office here, but I can do it through the [constituency association]. And when you're talking about memberships and donations, it's always about "This is what the MP has done ... for the people of [the riding]." So those are the sorts of things that I can't put out through my office but I can communicate it though my [constituency association].

Executives also organize events through which MPs' legislative accomplishments can be communicated to constituents in an explicitly partisan manner. Like other forms of communication, MPs are careful to distinguish between representative and partisan events. MPs and their staff schedule community meetings and events that must not be partisan in nature. However, this is hardly a concern when the constituency associations organize such events. MPs are permitted to deliver campaignstyle speeches trumpeting their service responsiveness to the riding. Members of the executives use these opportunities to listen for service requirements and highlight the representative efforts of the MP.

\subsection{Policy responsiveness}

Constituency association executives also enhance MPs' policy responsiveness in the ridings. The first way that executive members do so is by providing MPs with a sense of what their constituents are thinking on certain pertinent issues. MPs may come to executive meetings hoping to 
draw insight on how constituents feel on prospective policy issues that are or may soon become important.

In some instances, executives are a source of innovation benefits, providing MPs with ideas that are derived directly from their own sectors. However, in most cases, the relationship is more nuanced. MPs often find themselves in situations where they must justify policies determined by the party leader. While policy ideas may be debated in the constituencies, MPs generally accept the prerogative under the parties' franchise bargains that the party leadership ultimately makes important policy decisions (Carty, 2002: 11). Since Canadian parties are characterized by strong discipline and non-compliant MPs may be punished, MPs are unlikely to rebel once a decision has been made. In these cases, constituency association executives assist MPs by providing feedback on policy and allowing the MP to test new policies and suggesting different methods of communicating or marketing policy ideas in order to render them more acceptable to constituents. Executive members are able to fulfill these roles more effectively if they are representative of the sectors of the ridings.

Within this context, executive members perform two functions. First, executive members provide feedback on the party and the MP's policies. This is particularly true if the party is proposing measures that are unpopular in the riding, forcing the MP into positions that will not be seen as responsive to the policy positions of the constituency. MPs who spend a significant amount of time among political staff in Ottawa value this feedback from executive members because it is drawn from the riding and from executive members' conversations and experiences in their own sectors. MP1 summarized these different benefits.

They give me honest feedback. They're not sycophants. If they think we're screwing up, they tell me, and I appreciate that. They are a good sounding board because they live all over the riding ... they bring to me what people are saying at Tim Horton's or the grocery store or wherever.

The second function that executives perform is assisting MPs in developing messages regarding their representative activities that can be communicated to constituents. Since MPs are often saddled with party policies and leaders' decisions that will be harmful to their reputations for policy responsiveness in their constituencies, executives assist MPs by presenting issues in ways that will be acceptable to their constituencies. This process plays out in a variety of ways during executive meetings that come to resemble focus groups. Some MPs test unpopular ideas by attempting to convince the members of their executive that they are in fact good policies. If the executive is representative of the riding as a whole, then doing so is useful preparation for explaining the policies to 
constituents. "If you're contemplating an idea for the constituency, why not float it with your own supporters first?" asked one MP.

MP6 from a rural riding employed this technique to justify his vote on the divisive issue of same-sex marriage:

Take my vote on same-gender marriage. I voted in support of that. It was a very controversial issue at the time, one that very largely divided Canadians and one that my executive did not originally support. So ... I had to explain it to them. And once I was able to do that, I knew that I could explain it to the rest of the riding.

The reason that the MP thought this was because he was confident that the executive contained representatives from all local sectors and therefore was a microcosm of the constituency as a whole.

Executives also actively assist MPs in tailoring messages for local consumption. Executives are able to report back on what they are hearing in local sectors and use this information to help craft a message that will boost the local perception of policy responsiveness. MP1 worked with his executive to develop a saleable message concerning the government's 2008 decision to prorogue Parliament:

Some of the more controversial things we've done ([for example, ] prorogation) ... I've got a lot of feedback. Generally, the perception was not positive about that. But we were trying to get our message out about what it really meant, and I was able to get some feedback from [executive members]. "Okay, the message is not really working, we need to change it." That sort of thing.

In the same way that inter-election maintenance events sponsored by local constituency associations give MPs opportunities to enhance their reputations for service responsiveness, so too do these events allow MPs to listen to policy opinions from the riding and communicate back their own views in order to establish a reputation for policy responsiveness. MPs also encourage executive members to return to their sectors and explain their policy positions, further boosting their policy congruence with constituents.

The experience of MP7 illustrates how executive members can play a role in helping to establish policy responsiveness. Bill was forced to explain an unpopular policy from the federal government that would be contained in an upcoming budget. The monthly executive meeting provided an opportunity for the MP to explain the government's decision and explore ways of presenting this decision to his constituents in an acceptable manner:

I talked to them about a couple of ... things that were directly in the budget...There were people that were hoping that the home renovation tax credit would 
be extended. But what I indicated to them ... was if we were going to extend this, there would have been an expectation of extension on everything.

This was a process of both learning and persuasion. The MP asked for views from the riding, he received disapproving views and he worked to convince executive members that the decision already taken by the party leadership was in fact the correct one. From these discussions, the MP learned that his constituents could be persuaded if the policy decision was accompanied by the argument that the government was in fact doing what it had previously promised, and that there had always been a strict time limit on the tax credit. Having developed a message through these discussions that he could present to constituents, he encouraged executive members to relay this message back to the riding. Since his executive members were representative of what he perceived to be the predominant sectors of the riding, the MP trusted them to communicate this message in order to establish a form of policy responsiveness in the riding.

I really encouraged everyone to carry the message out that we're doing exactly what we said we would do. And, interestingly, I'm hearing back from people that weren't at the [meeting] that are ... saying, "You know, ... you're doing exactly what you said you would do." So this is a system of people going back out and talking to people. It's coffee talk, it's Tim Horton's talk, it's just them and their everyday lives, the people that they're coming into contact with. If the issue comes up or if it's mentioned, it's a really informal way of getting a message out. For me, it's very effective.

In this way, the executive members completed the circle of effective representation: first by providing the MP with a perspective on the policy preferences of his constituents and, second, by carrying policy messages - conditioned as a result of the MPs' discussions with his executive members - back to those constituents.

\subsection{Symbolic responsiveness}

Constituency associations also enhance MPs' symbolic responsiveness within their ridings. The first way that associations do so is by planning inter-election maintenance events. MPs enhance perceptions of symbolic responsiveness simply by attending, conversing with constituents and participating.

A distinction must be made between events organized by MPs' offices and constituency associations. MPs' offices occasionally organize community outreach events or meetings for the MP to meet and converse with constituents. These occasions also allow the MP to accumulate symbolic responsiveness. By organizing inter-election events, the constituency association boosts the number of events through which the MP can 
converse with constituents. This latter type of event has the added bonus of being explicitly partisan in nature.

MP8 was deeply appreciative of such an event organized by members of his constituency association. "They plan it, ... it's a big enterprise, we go through like two thousand hot dogs," he notes. "The zoo brings their camel, and it's a whole big thing ... It's sort of a repeating civic engagement thing on their part." This event draws a significant number of young families in the MP's suburban riding. Since the event is designed as a community outreach gathering, the costs of attending are very low, which attracts families from the urban riding's low-income neighbourhoods. This means that the association absorbs substantial costs in order to host the event. One of the benefits, however, is that the MP delivers a speech and talks with citizens. The benefits for his symbolic responsiveness in the riding are perceived to be substantial.

The second way that constituency association executive members enhance MPs' symbolic responsiveness is by alerting them to events in their sectors that MPs may wish to attend in order to make an appearance and construct a bond with constituents. Once again, this is based on the sectors present. Urban MPs place great emphasis on attending cultural events in their ridings and rely on executive sector representatives to keep them informed of upcoming events. In contrast, MPs in rural seats depend on executive members to keep them up to date on events in the far-flung communities of their ridings.

Finally, constituency association executives assist MPs in developing symbolic responsiveness by occasionally standing in for the MP when the MP is unable to attend particular events, especially because of duties in Ottawa. Notes MP9:

Sometimes I'll ask a member to represent me at an event that I've been invited to but I'm [in Ottawa] or I'm elsewhere and I can't go. I'll ask a member to go on my behalf and to say a few words on my behalf ... I think that's an indication of what we're trying to do ... to extend our presence and show that, in the community, we care. And, of course, that person who represents me will come back and give me feedback.

By sending an executive member to stand in for him, the MP is also provided the opportunity to learn what constituents were discussing at the event.

\section{MPs and Their Associations}

The last section described how constituency association executives assist MP in carrying out their representational functions. This raises the question of why some MPs use their constituency association executives as 
communications vehicles to augment their representational abilities whereas others do not do so. In this section, I briefly explore variation in this phenomenon and specify two necessary conditions for MPs to use their associations in this manner: (1) knowledge of both the functions and potential of constituency associations and (2) trust in the abilities of the members of their associations. In order to employ their associations as representative vehicles, MPs must be both aware of the potential afforded them by their associations and sufficiently confident in the abilities of their executives to carry out representational tasks. Three factors - length of time in office, party affiliation and previous experience in party organizations - influence MPs' knowledge of and trust in their associations. The small-n nature of this research means that these findings cannot be generalized to all MPs, and the following analysis is therefore exploratory in nature. However, the following arguments generated from deep analysis of a small number of cases can be tested in future large-n studies of MPs and their constituency associations.

First, what variation exists in how MPs use associations as communications vehicles? One consequence of the open-ended and later semistructured interviews conducted for this research is that the responses of all MPs studied cannot be compared in a meaningful manner, as openended interviews do not necessarily produce comparable data (for example, Small, 2009). Nevertheless, it is clear that most MPs interviewed employed members of their association executives as communications vehicles. Indeed, most MPs who were asked how their associations benefited them first replied by describing representative rather than electoral benefits. A comparably small number of MPs either expressed doubt about the ability of associations to perform these functions or were uninterested in the input associations might provide. MPs' discussions of this topic provide clues as to what is necessary for them to use their associations as representative vehicles.

In order to use their associations in this manner, MPs must both have knowledge of associations' representative function and trust executive members to carry out this task effectively. The most important factor influencing these conditions is length of time in office. Over time, particularly after a single term in office, MPs learn of the functions of associations - sometimes from conversations and interactions with other MPs - and come to expect their own associations to carry out these roles. Time also provides association members with opportunities to gain trust from MPs by successfully carrying out the tasks they are given.

In some cases, this is a natural process as MPs gain familiarity and trust in the existing members of the executive. But more often the cyclical nature of party organization in the ridings means that MPs have opportunities to construct their executives from the ground up (Carty, 1991: 174), particularly of personal supporters from their previous nomination 
and campaign teams and, later, from the local sectors they perceive to be important in their ridings (see Koop, 2011: 78). Time is necessary for new MPs to construct executives that they themselves can trust, so MPs with at least a single term in office are more likely than neophytes to use their associations as representative vehicles.

Second, partisan affiliation plays a role in shaping both familiarity with and trust in constituency associations. First-term MPs in the Liberal and Conservative parties are more likely than New Democrats to have won their party nominations as outsiders with limited previous experience in party organizations; these MPs therefore require time to build knowledge of and trust in their associations (Sayers, 1999: 43). In contrast, NDP candidates are more likely to have a record of service in the party; firstterm NDP MPs therefore tend to be both familiar with the functions of associations and have a pre-existing working relationship with members of their executives. NDP MPs therefore begin to rely on their associations to function as representative vehicles more quickly than Conservative and Liberal MPs and will not require the time needed by Conservative and Liberal MPs to develop confidence and trust in their executives.

While such previous experience in party organizations is common among first-time NDP MPs, it is not exclusive to them. All MPs with previous experience in constituency party organizations are more likely to use their associations as communications vehicles, since they have knowledge of associations' functions and, if they are from the riding, a familiarity with the members of the executive. One first-time Liberal MP, for example, brought substantial experience as a constituency association president to her role as MP. Upon being elected she drew on this experience to compose a list of expectations that she had for the association in her riding; the first priority on this list was to construct a network of executive members to maintain communication with local sectors. It was her previous experience in party constituency associations that allowed the MP to compose this list.

\section{Discussion and Conclusion}

Constituency associations play important representational roles in the ridings by facilitating communication between MPs and their constituents. Members of association executives gather information regarding the needs and preferences of constituents in order to communicate this information to MPs and disseminate the representative accomplishments of MPs to constituents. Their roles as sector representatives enhance executive members' ability to perform these functions. The result is that executives assist MPs in developing service, policy and symbolic responsiveness in their ridings. 
The identification of a representational role for association executives provides a counterbalance to the view that Canadian political parties are both unrepresentative of and inaccessible to Canadians. Association executives provide a means for MPs to learn of the ongoing needs and concerns of their constituents and in so doing enhance the ability of MPs to effectively represent those constituents. Furthermore, while the policy development processes of Canada's brokerage parties are largely inaccessible to Canadians (Cross, 2007: 425), citizens may nevertheless play important roles in the representational process in the ridings. MPs want their executives to be more representative of their ridings; they encourage citizens to join their associations; and they worry when the composition of their executives do not meet their standards. Just as citizens can play important roles in candidate selection by joining constituency associations and voting in nomination contests, so too can they play important roles in the representational process by doing so.

However, there are three limitations on the extent to which executives enhance the quality of local representation. First, executive members are either self-selected or chosen by MPs to sit on executives and facilitate communicate between their communities and their MPs. Executive members are not selected by their own sectors and so may not be truly aware of the needs and preferences of those communities. Some MPs are aware of this limitation; one acknowledged this in referring to "self-appointed representatives" of local communities.

Second, executive members play a relatively passive role in the representational process. Despite that some MPs claim to seek and value criticism from their executives, there are no mechanisms available for executives to hold MPs to account beyond removing their support in future re-nomination and re-election campaigns. Within a structure where exit trumps voice (Carty, 2002: 728), executive members who cannot work with MPs are more likely to depart than attempt to argue in favour of meeting service needs or policy preferences that MPs are unwilling to address. And, as was seen in the last section, some MPs are not interested in using their executives for representational purposes.

Finally, the danger to MPs of relying on party structures for information about the needs and preferences of constituents is that those needs and preferences may be skewed in a partisan manner. Sector representatives may focus on certain issues that accord with the priorities of the party and downplay those that do not. Indeed, partisanship permeates these informal structures from the start, as MPs' partisanship shapes their conceptions of important local sectors, which in turn influences the sector representatives they seek out to serve on their executives. Furthermore, the partisan nature of association executives means that by turning to them for information about needs and preferences, MPs are privileg- 
ing the concerns of co-partisans over constituents in general, a tendency already well recognized in the American literature on the "electoral connection" between constituent preferences and congressional behaviour (for example, Mayhew, 1974; Miller and Stokes, 1963).

The description of MPs and their constituency associations provided by Carty, Cross and Young- - "cadre-style organizations of electorally oriented local partisans gathered around a parochial politician" (2000: 17) - holds true. Canadian constituency associations are hardly massstyle organizations with extensive memberships from throughout local sectors communicating preferences to MPs and holding them to account when the MP fails to act in accordance with their wishes. Instead, they are typically reduced between elections to their cores: the local executives. These small cadres of partisan loyalists often serve with the approval of MPs, who call upon executive members to act as communications vehicles between their own distinctive communities and the MP. While associations may improve the quality of local democracy, they themselves are not particularly democratic institutions.

Nevertheless, this article demonstrates that these small cadre-style organizations have crucial, perhaps indispensible, representational roles to play between election campaigns by enhancing communication between MPs and constituents. Constituency associations provide a means for MPs to learn of the needs and preferences of their constituents and to communicate their accomplishments back to those constituents. While this article has focused on party organizations, future work may focus on other mechanisms that Canadian MPs rely on in order to both learn of constituency needs and to communicate their representative accomplishments back to constituents.

\section{Notes}

1 The majority of MPs I spoke to admit to playing at least a small role in the selection of executive personnel. Those who did not do so cited two reasons for their lack of intervention. First, a small number of MPs were uninterested in the activities of the association and did not see the selection of personnel as a productive use of their time. Second, two MPs were opposed to interfering in the process out of principle, arguing that association members had a right to select executives free from interference from the MP.

2 I quote from the following nine interviews with sitting MPs. MP1 is a Conservative MP from an urban Alberta riding. MP2 is a Liberal MP from a rural Quebec riding. MP3 is a Liberal MP from an urban Ontario riding. MP4 is an NDP MP from a rural Ontario riding. MP5 is a Conservative MP from a rural Ontario riding. MP6 is a Conservative MP from a rural Nova Scotia constituency. MP7 is a Conservative MP from an urban Ontario riding. MP8 is a Liberal MP from an urban Ontario constituency. MP9 is a Liberal MP from an urban Quebec constituency. All interviews were conducted by the author.

3 A small number of MPs also reported communicating to executive members on a one-on-one basis, especially if they required information regarding a specific sector. 
However, all of the MPs who reported doing so also regularly consulted with the executive as a whole.

\section{References}

Blais, Andre, Elisabeth Gidengil, Agnieszka Dobrzynska, Neil Nevitte and Richard Nadeau. 2003. "Does the Local Candidate Matter? Candidate Effects in the Canadian Election of 2000." Canadian Journal of Political Science 36: 657-64.

Carty, R. K. 1991. Canadian Political Parties in the Constituencies. Toronto: Dundurn Press.

Carty, R. K. 2002. "The Politics of Tecumseh Corners: Canadian Political Parties as Franchise Organizations." Canadian Journal of Political Science 35: 723-45.

Carty, R. Kenneth, William Cross and Lisa Young. 2000. Rebuilding Canadian Party Politics. Vancouver: UBC Press.

Carty, R.K. and William Cross. 2010. "Political Parties and the Practice of Brokerage Politics." In The Oxford Handbook of Canadian Politics, ed. John C. Courtney and David E. Smith. Toronto: Oxford University Press.

Carty, R. K. and Munroe Eagles. 2005. Politics is Local: National Politics at the Grassroots. Oxford: Oxford University Press.

Clark, Alistair. 2004. "The Continued Relevance of Local Parties in Representative Democracies." Politics 24: 35-45.

Cross, William. 2007. "Policy Study and Development in Canada's Political Parties." In Policy Analysis in Canada: The State of the Art, ed. Laurent Dobuzinskis, Michael Howlett and David Laycock. Toronto: University of Toronto Press.

Dahl, Robert A. 1989. Democracy and Its Critics. New Haven: Yale University Press.

Denver, David and Gordon Hands. 2007. Modern Constituency Electioneering: Local Campaigning in the 1992 General Election. London: Frank Cass.

Docherty, David C. 1997. Mr. Smith Goes to Ottawa. Vancouver: UBC Press.

Eulau, Heinz and Paul D. Karps. 1977. "The Puzzle of Representation: Specifying Components of Responsiveness." Legislative Studies Quarterly 2: 233-54.

Fenno, Richard F. 1978. Home Style: House Members in their Districts. Boston: Little, Brown, and Co.

Jewell, Malcolm Edwin. 1982. Representation in State Legislatures. Lexington: University Press of Kentucky.

Key, V.O. 1961. Public Opinion and American Democracy. New York: Knopf.

Koop, Royce. 2010. "Professionalism, Sociability, and the Liberal Party in the Constituencies." Canadian Journal of Political Science 43: 893-913.

Koop, Royce. 2011. Grassroots Liberals: Organizing for Local and National Politics. Vancouver: UBC Press.

Lijphart, Arend. 1971. "Comparative Politics and the Comparative Method." American Political Science Review 65: 682-93.

MacLeod, Peter. 2006. "How to Organize an Effective Constituency Office." Canadian Parliamentary Review 29: 9-12.

Malloy, Jonathan. 2003. "High Discipline, Low Cohesion? The Uncertain Patterns of Canadian Parliamentary Party Groups." The Journal of Legislative Studies 9: 116-29.

Mayhew, David R. 1974. Congress: The Electoral Connection. New Haven and London: Yale University Press.

Mays, Nicholas and Catherine Pope. 2000. "Assessing Quality in Qualitative Research." British Medical Journal 320: 50-52.

McMenemy, John. 1989. "Getting to Know the Parties by the Company We Keep: Local Sources of Party Imagery." In Canadian Parties in Transition, ed. Alain-G. Gagnon and A. Brian Tanguay. Toronto: Nelson Canada. 
Miller, Warren E. and Donald E. Stokes. 1963. "Constituency Influence in Congress." American Political Science Review 57: 45-56.

Pitkin, Hanna Fenichel. 1967. The Concept of Representation. Berkeley: University of California Press.

Price, Richard G. and Maureen Mancuso. 1995. "Ties that Bind: Members and Their Constituencies." In Introductory Readings in Canadian Government and Politics, ed. Robert M. Krause and R.H. Wagenberg. Toronto: Copp Clark.

Sandelowski, Margarete. 1994. "Focus on Qualitative Methods: The Use of Quotes in Qualitative Research." Research in Nursing Health 17: 479-82.

Sayers, Anthony M. 1999. Parties, Candidates and Constituency Campaigns in Canadian Elections. Vancouver: UBC Press.

Scarrow, Susan E. 1996. Parties and Their Members: Organising for Victory in Britain and Germany. Oxford: Oxford University Press.

Small, Mario Luis. 2009. "How Many Cases Do I Need? On Science and the Logic of Case Selection in Field-Based Research." Ethnography 10: 5-38.

Smith, Michael A. 2003. Bringing Representation Home: State Legislators among Their Constituencies. Columbia: University of Missouri Press.

Soroka, Stuart, Erin Penner and Kelly Blidook. 2009. "Constituency Influence in Parliament." Canadian Journal of Political Science 42: 563-91.

Whiteley, Paul and Patrick Seyd. 2003. "How to Win a Landslide by Really Trying: The Effects of Local Campaigning on Voting in the 1997 British General Election." Electoral Studies 22: 301-24.

Wolinetz, Steven B. 2007. "Cycles and Brokerage: Canadian Parties as Mobilizers of Interest." In Canadian Parties in Transition, ed. Alain-G. Gagnon and A. Brian Tanguay. Peterborough ON: Broadview. 
Reproduced with permission of the copyright owner. Further reproduction prohibited without permission. 